\title{
Study of Magnetite Nanoparticles by the Method of Mössbauer Spectroscopy
}

\author{
G. I. KRIVEN ${ }^{1,2}$, YING SUN ${ }^{3}$, \\ ${ }^{1}$ Moscow Aviation Institute (National Research University), \\ Moscow, Volokolamskoe shosse, 4, 125993, \\ RUSSIA \\ ${ }^{2}$ Institute of Applied Mechanics of RAS, \\ Moscow, Leningradsky prt. 7, 125040, \\ RUSSIA \\ ${ }^{3}$ Department of Mechanical Engineering, \\ Hangzhou Xiaoshan Technician College, \\ Hangzhou Zhejiang, 448 Tonghui South Road, Xiaoshan District, 311200, \\ CHINA.
}

\begin{abstract}
In this work, we studied the Mössbauer spectra of magnetite samples of various compositions. To protect magnetite from oxidation, the resulting particles are coated with protective shells, among which silanes are promising, which polymerize on the surface of magnetite nanoparticles, forming strong covalent bonds. The coating of nanoparticles protects them from aggressive environmental influences, evens out their size distribution, and also protects the environment from the possible toxic effects of the particles themselves.

It was shown that the magnetite phase predominates in the sample of native particles, the coating of native particles with alkoxysilane does not lead to fundamental changes in the phase state of the sample particles, and oxidation with nitric acid leads to the complete transformation of magnetite into maghemite. It is obvious that the reason for the distortions of the relaxation nature in the Mössbauer spectra of the samples is the small sizes of the iron-containing domains, which allows us to consider the description of the spectra within the framework of the model of multilevel superparamagnetic relaxation.
\end{abstract}

Keywords-Nanoparticles, magnetite, spectroscopy, silanes.

Received: March 27, 2021. Revised: September 1, 2021. Accepted: September 13, 2021. Published: September 21, 2021.

\section{Introduction}

I

$\mathrm{T}$ document is known that magnetite particles are sensitive to oxidation, which can lead to the appearance on the particle surface of a modified layer, the magnetic properties of which may differ from the particle core, leading to a decrease in the saturation magnetization. In addition, due to Van der Waals forces, particles tend to agglomerate. Thus, there is a need to stabilize magnetite nanoparticles [1]-[13]. This will make it possible to control the size of the resulting particles, prevent their aggregation after synthesis, protect the resulting particles from the aggressive oxidative effects of the environment, and the environment itself from the toxic effect of the nanoparticle. There is a wide range of substances capable of forming a protective shell on the surface of magnetite nanoparticles; among them, alkoxysilanes are of interest as inert, biocompatible, and functional inorganic ligands. There are many publications devoted to the synthesis and characterization of silica-coated iron oxide nanoparticles.
There are several ways to synthesize composite nanoparticles [14]-[30].

Modern composites have not only a wide range of physical and mechanical properties, but are also capable of directionally changing them, for example, increasing fracture toughness, regulating rigidity, strength, and other properties. These possibilities are expanded when fibers of different nature and geometry are used in composites, i.e., when creating hybrid composites. In addition, these materials are characterized by the appearance of a synergistic effect (coordinated joint action of several factors in one direction) [31]-[47].

The properties of the interface or interfacial zone, first of all, the adhesive interaction between the fiber and the matrix, determine the level of properties of composites and their retention during operation. Local stresses in the composite reach their maximum values just near or directly at the interface, where material destruction usually begins. The interface must have certain properties to ensure efficient 
transfer of the mechanical load from the matrix to the fiber. The adhesion bond at the interface should not be destroyed under the action of thermal and shrinkage stresses arising from the difference in the temperature coefficients of linear expansion of the matrix and fiber or as a result of chemical shrinkage of the binder during its curing.

When creating nanocomposites, the key tasks are the development of efficient, reliable, and affordable production technologies for mass production, which make it possible to obtain materials with stable characteristics. The hand lay technique, also called wet lay, is the simplest and most widely used process for producing flat reinforced composites. The process consists of laying layers of a polymer in successive layering using an epoxy matrix. Wet-laying is a molding process that combines layers of reinforced carbon fiber with epoxy to create a high-quality laminate. Before starting the installation process, you must prepare the appropriate form. This preparation consists of cleaning the table and applying a release agent to the surface. The manual laying process can be divided into four main steps: mold preparation, epoxy coating, laying and curing. Form preparation is one of the most important steps in the installation process. This process requires dry reinforcement layers and the application of a wet epoxy matrix. They are connected together - reinforcing material, impregnated with a matrix

Nanoparticles, even with a very low volumetric content (less than $1 \%$ ), are contained in such a fragment in a very large amount, and it is impossible to model their effect at this scale level. For example, a cubic fragment of a $1 \mu \mathrm{m}$ matrix contains more than thousand nanoparticles for a given volumetric content. Therefore, in particular, the nano-modified binder is white, while the usual binder is yellow. To model such materials, it is necessary to resort to multiscale approaches and to carry out a consistent determination of effective properties at various scale levels. This task is greatly simplified if the properties of the nanomodified matrix are known from experiments. In particular, it is known that its Young's modulus is $2.5 \mathrm{GPa}$. The missing characteristic is Poisson's ratio, which can be approximately taken unchanged, or estimated on the basis of analytical calculations using the found value of the "effective" volumetric content of the filler, which was done. Further, it suffices to numerically solve the averaging problem on a representative fragment containing only nanoparticles.

Coatings on nano and micro-sized particles can serve for many purposes. First of all, modification of the surface with coatings makes it possible to make the particles compatible with various matrixes [14]-[30]. For medical purposes, the biocompatibility with the environments of a living organism is of crucial importance. It is equally important that coatings can significantly enhance or decrease the sorption properties of magnetically controlled sorbents. This provides prerequisites for the creation of magnetically controlled particles with specific sorption properties. It is also known that the coatings prevent the core from leaching out. The presence of a coating also often facilitates the stabilization of particles in an environment with an alkaline $\mathrm{pH}$ or significant salt concentration. For example, the isoelectric point of $\mathrm{SiO}_{2}$ is reached at $\mathrm{pH} 2-3$. Therefore, the particles coated with silica are negatively charged at the $\mathrm{pH}$ of the blood, which causes electrostatic repulsion, which avoids the formation of clumps.

In order to derive the equation of the adsorption isotherm, a number of simplifications are introduced. All the places where the adsorbed particles are fixed are the same, and adsorption on one of them does not affect the state of the other. The interaction between the adsorbed particles is negligible. The adsorption layer is monomolecular, i.e. it consists of one layer of molecules. In this case, the bond of the adsorbate with the adsorbent is sufficiently strong, which excludes the movement of the adsorption complex along the surface of the adsorbent (localized adsorption).

Active (well absorbing) adsorbents have a very large specific surface area. For example, the absorbers most often used for scientific purposes and industrial practice - activated carbon, silica gel, zeolites - have $\mathrm{s}_{0}$ up to several hundred and even thousands of square meters per $1 \mathrm{~g}$.

The ability of the adsorbent to absorb the adsorbate is characterized by the amount of adsorption. The amount of adsorption is the excess mass of the adsorbate in the boundary layer over its mass in an equal volume of the environment, referred to the unit surface of the adsorbent.

Sometimes the adsorption value is expressed in moles of adsorbate per $1 \mathrm{~m}^{2}$ (or $1 \mathrm{~cm}^{2}$ ) of the adsorbent surface. Since quite often the surface of the adsorbent is unknown, the value of adsorption is expressed in moles of adsorbate per $1 \mathrm{~g}$ of adsorbent $(\mathrm{mol} / \mathrm{g})$. It is customary to evaluate the process of toxin sorption by the adsorbing surface using the curves of Langmuir sorption isotherms.

Silanol binding agents are applied directly to the surface of $\mathrm{Fe}_{3} \mathrm{O}_{4}$ nanoparticles by copolymerization of monomers or by direct silanization. The developed surface of nanoparticles leads to a high density of surface functional groups [48]-[71], which can fix a large number of biologically active substances [32]. The most common way to obtain $\mathrm{LF} \mathrm{Fe} \mathrm{F}_{4} / \mathrm{SiO}_{2}$ with a core-shell structure is the sol-gel method (Stober method), which consists in hydrolysis and polycondensation under alkaline conditions in ethanol [33].

In this regard, in this work, we performed a comparative analysis of the microstructure of magnetite nanoparticles synthesized by various methods before and after their modification with 3-aminopropyltriethoxysilane under various reaction conditions (in argon and during oxidation).

\section{Study of magnetite samples}

Methods for obtaining the studied samples of magnetite are presented in table 1. Chemical analyses of the synthesized samples were carried out by the standard procedure described in our previous studies [32]-[34]. 
Table 1. List of obtained samples of magnetite nanoparticles.

\begin{tabular}{|l|l|}
\hline Sample code & \multicolumn{1}{|c|}{ Sample description } \\
\hline M - EN & $\begin{array}{l}\text { Synthesis of magnetite from FeSO4 } \cdot \\
7 \mathrm{H} 2 \mathrm{O} \text { and EDTA with heating } \mathrm{T}=80^{\circ} \mathrm{C}\end{array}$ \\
\hline $\mathrm{M}-\mathrm{C}$ & $\begin{array}{l}\text { Synthesis of magnetite from } \mathrm{FeCl} 3 \cdot 6 \mathrm{H} 2 \mathrm{O} \\
\text { and } \mathrm{FeCl} 2 \cdot 4 \mathrm{H} 2 \mathrm{O}\end{array}$ \\
\hline $\mathrm{M}-\mathrm{A}$ & $\begin{array}{l}\text { Modification of sample M - With APTES } \\
\text { coating }\end{array}$ \\
\hline $\mathrm{M}-\mathrm{AO}$ & $\begin{array}{l}\text { Oxidation of sample M - A with nitric acid } \\
\mathrm{HNO} 3\end{array}$ \\
\hline
\end{tabular}

An analysis of the sample M - EN, obtained by oxidation of $\mathrm{Fe}^{2+}$ with the formation of a complex with EDTA, was carried out by IR spectrometry. The image of the obtained spectrum is shown in Figure 1.

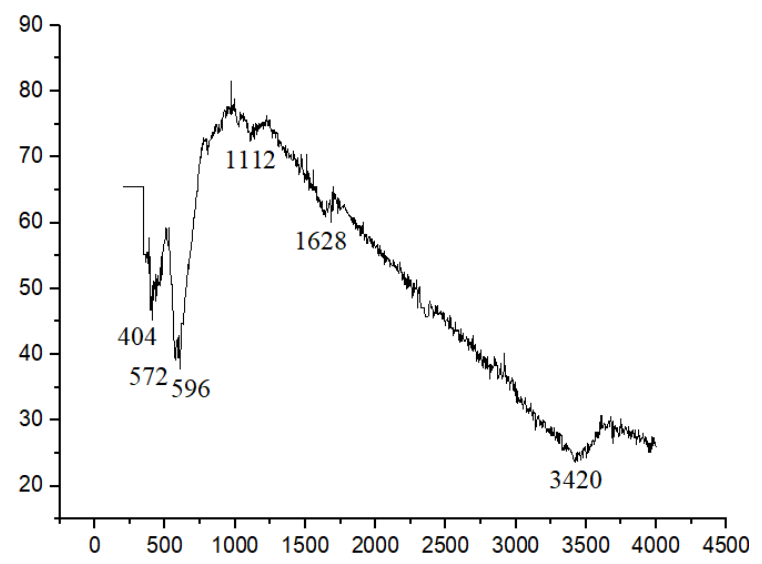

Fig. 1 ir spectrum for sample M - EN.

The characteristic absorption band at a wavelength of 572 $\mathrm{cm}^{-1}$ refers to the characteristic absorption bands of the Fe-O bond in $\mathrm{Fe}_{3} \mathrm{O}_{4}$, which is evidence of the formation of magnetite nanoparticles. A low intensity absorption band at a wavelength of $1628 \mathrm{~cm}^{-1}$ corresponds to asymmetric vibrations of the carboxylate group COO-, indicating binding with free $\mathrm{Fe}^{2+} / \mathrm{Fe}^{3+}$ ions or surface magnetite ions. The broad absorption band at $3420 \mathrm{~cm}^{-1}$ is a characteristic region of vibration of the $\mathrm{OH}-$ groups of water.

Mössbauer absorption spectra were obtained on an MS1104EM express Mössbauer spectrometer. The noise / signal ratio in the obtained spectra did not exceed $1 \%$. The experimental Mössbauer spectra were mathematically processed for high-resolution spectra (1024 points) using the SpectRelax 2.4 software. Chemical shift values are given relative to $\alpha$-Fe. The spectra were described using two models based on the literature data on the Mössbauer parameters most likely for the considered samples of iron oxides: magnetite$\mathrm{Fe}_{3} \mathrm{O}_{4}$ and maghemite $\gamma-\mathrm{Fe}_{2} \mathrm{O}_{3}$.
Mössbauer spectra at room temperature for all samples have the form of distorted asymmetrically broadened sextets. In this case, the sextets are not symmetrical both in intensity and in width. So, for a sample of native particles 1-3, the resonance lines have a noticeably wider width and lower intensity than lines 4-6 (Figure 2). In this case, the intensities of the lines are the same within groups 1-2 and 5-6.

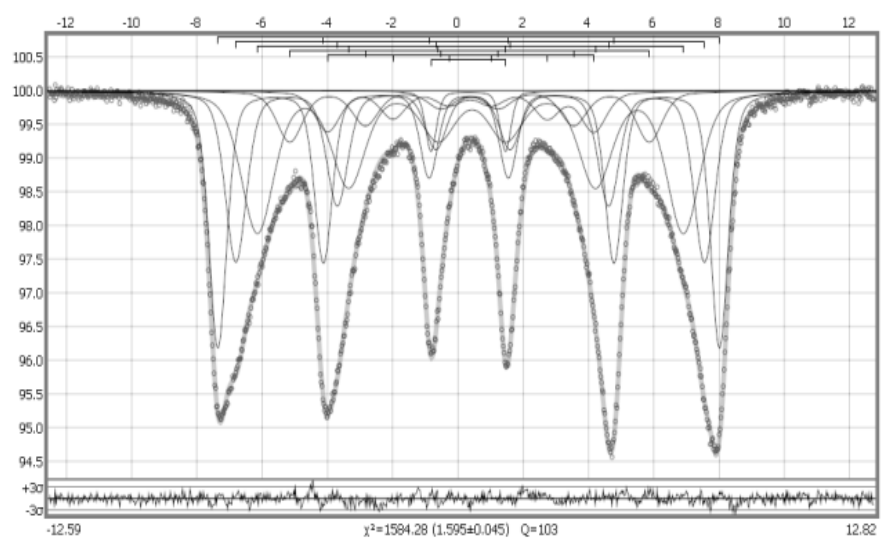

Fig. 2 Mössbauer spectrum of sample M - C at $295^{\circ} \mathrm{C}$.

All spectra can be satisfactorily described within a single model of five $(295 \mathrm{~K})$ or four $(78 \mathrm{~K})$ nested symmetric sextets and one symmetric doublet. In general, the models for different samples are similar to each other, and differ mainly in the ratio of the contributions of each of the subspectra for an individual sample. Thus, in the high-temperature spectra, the first, second, and third sextets have the largest areas (subspectra 1, 2, and 3, respectively). In the low-temperature spectra, the largest areas have 1 and 2 subspectra, and the areas of subspectra 3 and 4 that are close to each other in the samples of native and coated particles do not differ much from the area of subspectrum 2. These features, characterizing the distribution of iron atoms in crystallographic positions with different degrees of ordering of the local environment, distinguish these samples from magnetite, in which in the hightemperature spectrum one of the "internal" sextets (similar to subspectrum 4) had the largest area in addition to the outer sextet (similar to subspectrum 1) and the areas in the lowtemperature spectrum decreased monotonically from outer to inner.

As it can be also seen from the Fig. 2, the ultrafine parameters of the subspectra of the samples of native and coated particles are close at room temperatures. At the same time, based on the data at room temperature, all sextets can be divided into three groups. The first combines subspectra 1 and 4 with isomeric shifts corresponding to $\mathrm{Fe}^{3+}$ atoms in an octahedral oxygen environment. In the second, subspectrum 5 with an isomeric shift corresponding to $\mathrm{Fe}^{3+}$ atoms in a tetrahedral oxygen environment. And, finally, subspectra 2 and 3 , which have too large values of isomeric shifts for $\mathrm{Fe}^{3+}$ iron atoms in the octahedral environment, but too small for $\mathrm{Fe}^{2.5+}$ atoms in the octahedral voids of magnetite. Obviously, these sextets belong to iron atoms in octahedral voids of the oxidized form of nanomagnetite $-\delta-\mathrm{Fe}_{3} \mathrm{O}_{4}$, in which the 
proportion of $\mathrm{Fe}^{3+}$ significantly exceeds that of $\mathrm{Fe}^{2+}$. At low temperatures, sextets regroup (including due to the Verwey transition), but they can also be divided into $\mathrm{Fe}^{3+}$ atoms and partially reduced $\mathrm{Fe}^{(3-\mathrm{x})+}$.

The values of magnetic splitting obtained at room temperature are lower than those expected for bulk samples of magnetite and maghemite, which is typical for nanosized materials. The isomeric shifts of all subspectra of the sample of oxidized particles, obtained at room temperature, indicate that all atoms were oxidized to the $\mathrm{Fe}^{3+}$ oxidation state (octahedral positions). Even with low-temperature shooting, the isomeric shift of sextet 4 decreased significantly. Otherwise, the Mössbauer parameters did not undergo significant changes, except perhaps a noticeable increase in the widths of almost all subspectra, which may be associated with a decrease of the probability functions of the magnetic field distribution obtained for low-temperature Mössbauer spectra for all samples have the form of asymmetric unimodal peaks strongly shifted in the region of high fields (Fig. 3).
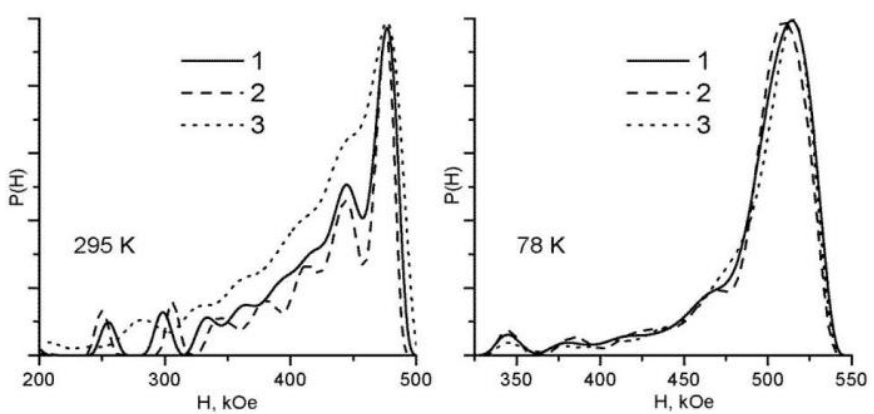

Fig. 3 Probability functions of magnetic field distribution: 1 sample M - C, 2 - sample M - A, 3 - sample M - AO.

As it can be seen from the Figure 3, the parameters of the probability functions practically do not differ from each other, except that for the sample of APTES-coated particles, the distribution maximum is located at a slightly lower field strength.

From the data presented in the Figure 3 one can also conclude that the probability functions of the distribution of hyperfine parameters for high-temperature spectra are different for different samples. Thus, for a sample of native particles, the field distribution has the form of a predominantly asymmetric bimodal peak, with maxima localized in the region of high fields, and an extended "wing" extending into low fields (Figure 3 ). In the sample of coated particles (with the same predominant asymmetric bimodal peak), this wing is slightly more resolved - three local maxima are clearly manifested on it. Before the beginning of this "wing", two weak "satellites" are observed for both samples in the region of 255 and $300 \mathrm{kOe}$. In the sample of oxidized particles, in contrast to their predecessors, there is practically no "fine structure" on the dependence of the probability of the distribution of magnetic fields - the distribution has the form of a noticeably wider unimodal peak, with the weighted average shifted to lower fields. This indicates a much wider size distribution of the sample particles (variants of the local environment). It is obvious that the reason for the distortions of the relaxation nature in the Mössbauer spectra of the samples is the small sizes of the iron-containing domains, which allows us to consider the description of the spectra within the framework of the model of multilevel superparamagnetic relaxation.

\section{Conclusion}

An examination of the data obtained makes it possible to show that systematic changes are observed in the experimental spectra, which are the same at different temperatures. Moreover, when passing from a sample of native particles to a sample of coated particles, these spectra changes are less than from a sample of coated particles to a sample of oxidized particles. Thus, this gives us possibility to make a conclusion that the treatment of the initial sample of magnetite with APTES leads to a narrowing of the external profile of the relaxation sextet, apparently due to the sharpening of the internal sextets. The processing of a sample of APTES coated particles with nitric acid caused the removal of components from the right side of the spectra, and the appearance of components in the left side of the spectrum, i.e. in fact, we are talking about a shift of some sextet to the region of low isomeric shifts, i.e. oxidation of iron.

This study was funded by RFBR, project number 21-3870008 .

\section{References}

[1] L. N. Rabinskiy, S. A. Sitnikov, "Development of technologies for obtaining composite material based on silicone binder for its further use in space electric rocket engines," Periodico Tche Quimica, 15(Special Issue 1), pp. 390-395, 2018.

[2] M. Sha, Y. A. Utkin, O. V. Tushavina, P. F. Pronina, "Experimental studies of heat and mass transfer from tip models made of carbon-carbon composite material (cccm) under conditions of high-intensity thermal load," Periodico Tche Quimica, vol.17, i. 35, pp. 988-997, 2020.

[3] P. F. Pronina, O. V. Tushavina, E. I. Starovoitov, "Study of the radiation situation in moscow by investigating elastoplastic bodies in a neutron flux taking into account thermal effects," Periodico Tche Quimica, 17(35), pp. 753-764, 2020.

[4] A. A. Orekhov, Y. A. Utkin, P. F. Pronina, "Determination of deformation in mesh composite structure under the action of compressive loads," Periodico Tche Quimica, 17(35), pp. 599-608, 2020.

[5] O. A. Pashkov, "Influence of Polymer Coatings on the Mechanical Properties of Steel Samples in Tensile and Bending Tests," Turkish Journal of Computer and Mathematics Education (TURCOMAT), vol. 12, no. 5, pp. 542-548, 2021.

[6] O. A. Pashkov, "Investigation of the Effect of Steel Plate Size and Elevated Temperature on Critical Load in 
Stability Tests," Turkish Journal of Computer and Mathematics Education (TURCOMAT), vol. 12, no. 10, pp. 1657-1663, 2021.

[7] Y. Sun, O. V. Egorova, E. L. Kuznetsova, "Identification of the front angle of a plane acoustic oblique pressure wave on convex surfaces with the use of analytical solution," Journal of the Balkan Tribological Association, 27(2), pp. 189-1976 2021.

[8] A. V. Babaytsev, L. N. Rabinskiy, K. T. Aung, "Investigation of the contact zone of a cylindrical shell located between two parallel rigid plates with a gap," INCAS Bulletin, 12(Special Issue), pp. 43-52, 2020.

[9] V. G. Dmitriev, O. V. Egorova, E. I. Starovoitov, "Particularities of mathematical modeling of deformation processes for arched and panel designs of composites with large displacements and rotation angles," INCAS Bulletin, 12(Special Issue), pp. 53-66, 2020.

[10] O. V. Egorova, E. I. Starovoitov, "Non-stationary diffraction problem of a plane oblique pressure wave on the shell in the form of a hyperbolic cylinder taking into account the dissipation effect," INCAS Bulletin, 12(Special Issue), pp. 67-77. 2020.

[11] O. A. Pashkov, "Theoretical calculation of the thickness of interphase zones in the Al-A12O3 composite," Turkish Journal of Computer and Mathematics Education (TURCOMAT), vol. 12, no. 10, pp. 1672-1677, 2021.

[12] O. A. Pashkov, "Experimental and Theoretical Study of Mechanical Properties of Matrix Composite Materials," Turkish Journal of Computer and Mathematics Education (TURCOMAT), vol. 12, no. 10, pp. 1678-1684, 2021.

[13]N. A. Kucheva, V. Kohlert, "Mathematical modeling methods for estimation the thermophysical properties of heat-protective composite materials," Turkish Journal of Computer and Mathematics Education (TURCOMAT), vol. 12, no. 10, pp. 1606-1612, 2021.

[14]O. A. Butusova, "Surface Modification of Titanium Dioxide Microparticles Under Ultrasonic Treatment," International Journal of Pharmaceutical Research, vol. 12, i. 4, pp. 2292-2296, 2020.

[15] O. A. Butusova, "Stabilization of Carbon Microparticles by High-Molecular Surfactants," International Journal of Pharmaceutical Research, vol. 12, Supplementary Issue 2, pp. 1147-1151, 2020.

[16] Yu. V. Ioni, A. Ethiraj, "New Tailor-Made Polymer Stabilizers for Aqueous Dispersions of Hydrophobic Carbon Nanoparticles," International Journal of Pharmaceutical Research, vol. 12, i. 4, pp. 3443-3446, 2020.

[17]N. A. Bulychev, E. L. Kuznetsova, "Ultrasonic Application of Nanostructured Coatings on Metals," Russian Engineering Research, 39 (9), pp. 809-812, 2019.

[18]N. A. Bulychev, V. V. Bodryshev, L. N. Rabinskiy, "Analysis of geometric characteristics of two-phase polymer-solvent systems during the separation of solutions according to the intensity of the image of micrographs," Periodico Tche Quimica, 16(32), pp. 551559,2019
[19] N. A. Bulychev, A. V. Ivanov, "Effect of vibration on structure and properties of polymeric membranes," International Journal of Nanotechnology, vol. 16, nos. 6/7/8/9/10, pp. $334-343,2019$.

[20] N. A. Bulychev, A. V. Ivanov, "Nanostructure of OrganicInorganic Composite Materials Based on Polymer Hydrogels," International Journal of Nanotechnology, vol. 16, nos. 6/7/8/9/10, pp. $344-355,2019$.

[21] N. A. Bulychev, A. V. Ivanov, "Study of Nanostructure of Polymer Adsorption Layers on the Particles Surface of Titanium Dioxide," International Journal of Nanotechnology, vol. 16, nos. 6/7/8/9/10, pp. 356 - 365, 2019.

[22]N. A. Bulychev, L. N. Rabinskiy, O. V. Tushavina, "Effect of intense mechanical vibration of ultrasonic frequency on thermal unstable low-temperature plasma," Nanoscience and Technology: An International Journal, 11 (1), pp. 15-21, 2020.

[23]N. A. Bulychev, L. N. Rabinskiy, "Ceramic Nanostructures Obtained by Acoustoplasma Technique," Nanoscience and Technology: An International Journal, 10 (3), pp. 279-286, 2019.

[24] Yu. V. Ioni, "Nanoparticles of noble metals on the surface of graphene flakes," Periodico Tche Quimica, vol. 17, no. 36, pp. 1199-1211, 2020.

[25] O. A. Butusova, "Vinyl Ether Copolymers as Stabilizers of Carbon Black Suspensions," International Journal of Pharmaceutical Research, vol. 12, Supplementary Issue 2, pp. 1152-1155, 2020.

[26] M. O. Kaptakov, "Catalytic Desulfuration of Oil Products under Ultrasonic Treatment," International Journal of Pharmaceutical Research, vol. 12, Supplementary Issue 2, pp. 1838-1843, 2020.

[27] B. A. Garibyan, "Enhancement of Mechanical Properties of Inorganic Glass under Ultrasonic Treatment," International Journal of Pharmaceutical Research, vol. 12, Supplementary Issue 2, pp. 1829-1832, 2020.

[28]M. O. Kaptakov, "Enhancement of Quality of Oil Products under Ultrasonic Treatment," International Journal of Pharmaceutical Research, vol. 12, Supplementary Issue 2, pp. 1851-1855, 2020.

[29] O. A. Butusova, "Adsorption Behaviour of Ethylhydroxyethyl Cellulose on the Surface of Microparticles of Titanium and Ferrous Oxides," International Journal of Pharmaceutical Research, vol. 12, Supplementary Issue 2, pp. 1156-1159, 2020.

[30] A. V. Perchenok, E. V. Suvorova, A. A. Farmakovskaya, V. Kohlert, "Application of vinyl ether copolymers for surface modification of carbon black," International Journal of Circuits, Systems and Signal Processing, vol. 15, pp. 1300-1304, 2021.

[31] A. V. Perchenok, E. V. Suvorova, A. A. Farmakovskaya, V. Kohlert, "Stabilization of aqueous dispersions of inorganic microparticles under mechanical activation," WSEAS Transactions on Applied and Theoretical Mechanics, vol. 16, pp. 127-133, 2021.

[32]A. N. Tarasova, "Vibration-based Method for Mechanochemical Coating Metallic Surfaces," 
International Journal of Pharmaceutical Research, vol. 12, Supplementary Issue 2, pp. 1160-1168, 2020.

[33]B. A. Garibyan, "Mechanical Properties of Electroconductive Ceramics," International Journal of Pharmaceutical Research, vol. 12, Supplementary Issue 2, pp. 1825-1828, 2020.

[34]M. O. Kaptakov, "Effect of Ultrasonic Treatment on Stability of $\mathrm{TiO}_{2}$ Aqueous Dispersions in Presence of Water-Soluble Polymers," International Journal of Pharmaceutical Research, vol. 12, Supplementary Issue 2, pp. 1821-1824, 2020.

[35] Yu. V. Ioni, "Synthesis of Metal Oxide Nanoparticles and Formation of Nanostructured Layers on Surfaces under Ultrasonic Vibrations," International Journal of Pharmaceutical Research, vol. 12, i. 4, pp. 3432-3435, 2020.

[36]A. N. Tarasova, "Effect of Reagent Concentrations on Equilibria in Water-Soluble Complexes," International Journal of Pharmaceutical Research, vol. 12, Supplementary Issue 2, pp. 1169-1172, 2020.

[37]A. N. Tarasova, "Effect of Vibration on Physical Properties of Polymeric Latexes," International Journal of Pharmaceutical Research, vol. 12, Supplementary Issue 2, pp. 1173-1180, 2020.

[38] Yu. V. Ioni, A. Ethiraj, "Study of Microparticles Surface Modification by Electrokinetic Potential Measuring," International Journal of Pharmaceutical Research, vol. 12, i. 4, pp. 3436-3439, 2020.

[39] Yu. V. Ioni, "Effect of Ultrasonic Treatment on Properties of Aqueous Dispersions of Inorganic and Organic Particles in Presence of Water-Soluble Polymers," International Journal of Pharmaceutical Research, vol. 12, i. 4, pp. 3440-3442, 2020.

[40] O. V. Tushavina, "Coupled heat transfer between a viscous shock gasdynamic layer and a transversely streamlined anisotropic half-space," INCAS Bulletin, 12 (Special Issue), pp. 211-220, 2020.

[41]S. Vakhneev, E. Starovoitov, "Damping of circular composite viscoelastic plate vibration under neutron irradiation," Journal of Applied Engineering Science, 18(4), pp. 699-704, 2020.

[42] V. A. Pogodin, L. N. Rabinskii, S. A. Sitnikov, "3D Printing of Components for the Gas-Discharge Chamber of Electric Rocket Engines," Russian Engineering Research, vol. 39, no. 9, pp. 797-799, 2019.

[43] Y. K. Kyaw, E. L. Kuznetsova, A. V. Makarenko "Complex mathematical modelling of mechatronic modules of promising mobile objects," INCAS Bulletin, 12(Special Issue), pp. 91-98, 2020.

[44] L. E. Kuznetsova, V. G. Fedotenkov, "Dynamics of a spherical enclosure in a liquid during ultrasonic cavitation," Journal of Applied Engineering Science, 18(4), pp. $681-686,2020$.

[45]A. V. Makarenko, E. L. Kuznetsova, "Energy-Efficient Actuator for the Control System of Promising Vehicles," Russian Engineering Research, 39(9), pp. 776-779, 2019.

[46]N. A. Kucheva, "Investigation of the mechanical properties of heat-protective highly porous composite materials using the effective medium model," Turkish Journal of Computer and Mathematics Education (TURCOMAT), vol. 12, no. 10, pp. 1613-1621, 2021.

[47] N. A. Kucheva, V. Kohlert, "Analytical solution of the problem of thermoelasticity for a plate heated by a source with a constant heat supply on one surface," Turkish Journal of Computer and Mathematics Education (TURCOMAT), vol. 12, no. 10, pp. 1622-1633, 2021.

[48]E. L. Kuznetsova, A. V. Makarenko, "Mathematic simulation of energy-efficient power supply sources for mechatronic modules of promising mobile objects," Periodico Tche Quimica, 15(Special Issue 1), pp. 330338, 2018.

[49] Y. Li, A. M. Arutiunian, E. L. Kuznetsova, G. V. Fedotenkov, "Method for solving plane unsteady contact problems for rigid stamp and elastic half-space with a cavity of arbitrary geometry and location," INCAS Bulletin, 12(Special Issue), pp. 99-113, 2020.

[50] E. L. Kuznetsova, G. V. Fedotenkov, E. I. Starovoitov, "Methods of diagnostic of pipe mechanical damage using functional analysis, neural networks and method of finite elements," INCAS Bulletin, 12(Special Issue), pp. 79-90, 2020.

[51]Y. K. Kyaw, P. F. Pronina, P. O. Polyakov, "Mathematical modelling of the effect of heat fluxes from external sources on the surface of spacecraft," Journal of Applied Engineering Science, 18(4), pp. 732-736, 2020.

[52] V. F. Formalev, S. A. Kolesnik, B. A. Garibyan, "Mathematical modeling of heat transfer in anisotropic plate with internal sinks," AIP Conference Proceedings, 2181, 020003, 2019.

[53] O. A. Butusova, "Design and Properties of Magnetically Controlled Sorbents," Turkish Journal of Computer and Mathematics Education (TURCOMAT), vol. 12, no. 5, pp. 515-519, 2021.

[54] O. A. Butusova, "Application of Magnetically Controlled Sorbents for Detoxication," Turkish Journal of Computer and Mathematics Education (TURCOMAT), vol. 12, no. 5, pp. 520-524, 2021.

[55] V. F. Formalev, S. A. Kolesnik, B. A. Garibyan, "Heat transfer with absorption in anisotropic thermal protection of high-temperature products," Herald of the Bauman Moscow State Technical University, Series Natural Sciences, (5), pp. 35-49, 2019.

[56] S. A. Kolesnik, N. A. Bulychev, "Numerical analytic method for solving the inverse coefficient problem of heat conduction in anisotropic half-space," Journal of Physics: Conference Series, 1474(1), 012024, 2020.

[57] V. F. Formalev, N. A. Bulychev, S. A. Kolesnik, M. A. Kazaryan, "Thermal state of the package of cooled gasdynamic microlasers," Proceedings of SPIE - The International Society for Optical Engineering, 11322, article number 113221B, 2019.

[58] M. O. Kaptakov, "Effect of Thin Polymer Layers on Mechanical Properties of Metal Surfaces," Turkish Journal of Computer and Mathematics Education (TURCOMAT), vol. 12, no. 5, pp. 525-529, 2021. 
[59]B. A. Garibyan, "Determination of the Elastic Modulus of the Coating Using a Spherical Indenter," Turkish Journal of Computer and Mathematics Education (TURCOMAT), vol. 12, no. 10, pp. 1594-1600, 2021.

[60] M. O. Kaptakov, "Modelling of Mechanical Properties of Metal Plates with Polymer Coatings," Turkish Journal of Computer and Mathematics Education (TURCOMAT), vol. 12 , no. 5, pp. 530-534, 2021.

[61]B. A. Garibyan, "Theoretical Estimations of Influence of Polymer Coatings on the Elastic Modulus and Ultimate Strength of Steel Samples," Turkish Journal of Computer and Mathematics Education (TURCOMAT), vol. 12, no. 10, pp. 1651-1656, 2021.

[62] M. O. Kaptakov, "Investigation of Effective Mechanical Characteristics of Nanomodified Carbon-Epoxide Composite by Numerical and Analytical Methods," Turkish Journal of Computer and Mathematics Education (TURCOMAT), vol. 12, no. 5, pp. 535-541, 2021.

[63] M. O. Kaptakov, "Obtaining of Carbon Fibers Based Composite Materials and Study of Their Mechanical Properties," Turkish Journal of Computer and Mathematics Education (TURCOMAT), vol. 12, no. 10, pp. 1601-1605, 2021.

[64] V. F. Formalev, S. A. Kolesnik, B. A. Garibyan, "Analytical solution of the problem of conjugate heat transfer between a gasdynamic boundary layer and anisotropic strip," Herald of the Bauman Moscow State Technical University, Series Natural Sciences, 5(92), pp. 44-59, 2020.

[65] Y. Sun, S. A. Kolesnik, E. L. Kuznetsova, "Mathematical modeling of coupled heat transfer on cooled gas turbine blades," INCAS Bulletin, 12(Special Issue), pp. 193-200, 2020.

[66]I. Kurchatov, N. Bulychev, S. Kolesnik, E. Muravev, "Application of the direct matrix analysis method for calculating the parameters of the luminescence spectra of the iron ion in zinc sulfide crystals," AIP Conference Proceedings, 2181, 020015, 2019.

[67]B. A. Antufev, E. L. Kuznetsova, L. N. Rabinskiy, O. V. Tushavina, "Investigation of a complex stress-strain state of a cylindrical shell with a dynamically collapsing internal elastic base under the influence of temperature fields of various physical nature," Asia Life Sciences, (2), pp. 689-696, 2019.

[68] B. A. Antufev, E. L. Kuznetsova, L. N. Rabinskiy, O. V. Tushavina, "Complex stressed deformed state of a cylindrical shell with a dynamically destructive internal elastic base under the action of temperature fields of various physical nature," Asia Life Sciences, (2), pp. 775782, 2019.

[69] L. N. Rabinskiy, O. V. Tushavina, "Problems of land reclamation and heat protection of biological objects against contamination by the aviation and rocket launch site," Journal of Environmental Management and Tourism, 10(5), pp. 967-973, 2019.

[70]A. N. Astapov, I. P. Lifanov, L. N. Rabinskiy, "Perspective Heat-Resistant Coating for Protection of
$\mathrm{Cf} / \mathrm{SiC}$ Composites in Air Plasma Hypersonic Flow," High Temperature, 57(5), pp. 744-752, 2019.

[71] V. N. Dobryanskiy, L. N. Rabinskiy, O. V. Tushavina, "Validation of methodology for modeling effects of loss of stability in thin-walled parts manufactured using SLM technology," Periodico Tche Quimica, 16(33), pp. 650656, 2020.

\section{Sources of Funding for Research Presented in a Scientific Article or Scientific Article Itself}

This study was funded by RFBR, project number 21-3870008 .

\section{Creative Commons Attribution License $\mathbf{4 . 0}$ (Attribution 4.0 International, CC BY 4.0)}

This article is published under the terms of the Creative Commons Attribution License 4.0 https://creativecommons.org/licenses/by/4.0/deed.en US 